\title{
How to B(e)-1 Important Cell During Leishmania Infection
}

\section{OPEN ACCESS}

Edited by:

Javier Moreno,

Carlos III Health Institute, Spain

Reviewed by:

Hira Nakhasi,

Center for Biologics Evaluation and

Research (FDA), United States

Salvador Iborra,

Complutense University of

Madrid, Spain

Angamuthu Selvapandiyan,

Jamia Hamdard University, India

${ }^{\star}$ Correspondence

Celio Geraldo Freire-de-Lima celio@biof.ufri.br

Herbert Leonel de Matos Guedes herbert@ioc.fiocruz.br;

herbert@biof.ufrj.br;

herbert@xerem.ufrj.br

Specialty section: This article was submitted to

Parasite and Host,

a section of the journal

Frontiers in Cellular and Infection

Microbiology

Received: 05 September 2019

Accepted: 28 November 2019

Published: 14 January 2020

Citation:

Firmino-Cruz L, Decote-Ricardo D,

Gomes DCO, Morrot A,

Freire-de-Lima CG and de Matos Guedes HL (2020) How to B(e)-1 Important Cell During Leishmania

\author{
Luan Firmino-Cruz ${ }^{1,2}$, Debora Decote-Ricardo ${ }^{3}$, Daniel Claudio de Oliveira Gomes ${ }^{4}$, \\ Alexandre Morrot ${ }^{5,6}$, Celio Geraldo Freire-de-Lima ${ }^{7 *}$ and \\ Herbert Leonel de Matos Guedes ${ }^{1,2,8 *}$
}

${ }^{1}$ Laboratório de Imunofarmacologia, Instituto de Biofísica Carlos Chagas Filho, Universidade Federal Do Rio de Janeiro, Rio de Janeiro, Brazil, ${ }^{2}$ Laboratório Interdisciplinar de Pesquisas Médicas, Instituto Oswaldo Cruz, Fundação Oswaldo Cruz, Rio de Janeiro, Brazil, ${ }^{3}$ Instituto de Veterinária, Universidade Federal Rural Do Rio de Janeiro, Seropédica, Brazil, ${ }^{4}$ Núcleo de Doenças Infecciosas/Núcleo de Biotecnologia, Universidade Federal Do Espírito Santo, Vitoria, Brazil, ${ }^{5}$ Laboratório de Imunopatologia, Instituto Oswaldo Cruz, Fundação Oswaldo Cruz, Rio de Janeiro, Brazil, ${ }^{6}$ Faculdade de Medicina, Universidade Federal Do Rio de Janeiro, Rio de Janeiro, Brazil, ${ }^{7}$ Laboratório de Imunomodulação, Instituto de Biofísica Carlos Chagas Filho, Universidade Federal Do Rio de Janeiro, Rio de Janeiro, Brazil, ${ }^{8}$ Núcleo Multidisciplinar de Pesquisa UFRJ-Xerém em Biologia (NUMPEX-BIO), UFRJ Campus Duque de Caxias Professor Geraldo Cidade, Universidade Federal Do Rio de Janeiro, Duque de Caxias, Brazil

B-1 cells are an innate-like population of B lymphocytes that are subdivided into B-1a and $\mathrm{B}-1 \mathrm{~b}$ distinguished by the presence or absence of CD5, respectively. B-1 cells can act as regulatory $\mathrm{B}$ cells, are able to present antigen and produce IL-10. Leishmaniasis in humans is a complex of diseases caused by parasites of the genus Leishmania. More than 20 species can infect humans, with each species causing the development of different immunological responses in the host. Susceptibility is usually related to the production of anti-inflammatory cytokines while the production of Th1 cytokines is indicative of resistance. However, few studies have attempted to evaluate the role of B-1 cells during either the in vivo infection or in vitro interaction with Leishmania parasites. In vivo studies were performed using XID mice model, BALB/Xid mice have a mutation in the Bruton's tyrosine kinase, which is an important enzyme for developing B-1 and maturing B-2 lymphocytes leading to the presence of immature B-2 cells. Here, we compile these studies and assess the influence of B-1 cells on disease progression with different Leishmania species.

Keywords: Leishmaniasis, BALB/XID, B-1 cells, B-1CDP cells, IL-10

\section{INTRODUCTION}

B-1 cells are an innate-like population of B cells that are subdivided into B-1a and B-1b by the expression, or lack of, the cell marker CD5, respectively (Kantor et al., 1992; Stall et al., 1992). While the B-1a subset can be generated from precursors in the fetal liver (Tung et al., 2006), the $\mathrm{B}-1 \mathrm{~b}$ subset is generated from precursors in the bone marrow (Tung et al., 2006) and can recognize a larger variety of antigens, including intracellular antigens (Cunningham et al., 2014). They are found mainly in the peritoneal and pleural cavities. B-1 cells have the ability to self-renew to survive long term, and have been shown to expand upon adoptive cell transfer. These cells can also secrete IgM without foreign antigen exposure (Kantor et al., 1992; Stall et al., 1992; Baumgarth, 2017), as well as naturally produce IL-10 (O'Garra and Howard, 1991).

The IL-10 production by B-1 cells was first suggested as an autocrine growth factor (O'Garra and Howard, 1991). However, a more recent study has shown that peritoneal B-1 cells from IL-10-knockout mice proliferate more than those from wild-type (WT) mice under LPS stimuli, 
which suggests that IL-10 could act by downregulating B-1 proliferation (Sindhava et al., 2010). It has since been speculated that the IL-10 produced by B-1 cells acts as an autocrine and paracrine regulator factor (Sindhava and Bondada, 2012).

In contrast to conventional B cells (B-2 cells), B-1 cells are able to develop immunogenic memory (Alugupalli et al., 2003; De Lorenzo et al., 2007), they can act as regulatory B cells (De Lorenzo et al., 2007) and they are also related to the innate immunity through their ability to present antigens (Vigna et al., 2006).

Parasites of the genus Leishmania are present worldwide with more than 20 species that can infect humans. The clinical manifestations differ from species to species, forming a complex of diseases collectively named leishmaniasis. These can be subclassified based on tissue tropism as either cutaneous leishmaniasis (CL), mucocutaneous leishmaniasis (MCL), and visceral leishmaniasis (VL). In CL, the host presents a single ulcerative lesion with swollen edges filled with parasites; however, diffuse cutaneous leishmaniasis (DCL) also can occur, where the host presents many non-ulcerative lesions filled with parasites all over the body, usually when there is pre-existing immunosuppression. In VL, also known as kalazar, the host presents high parasite burdens in the spleen and liver, and when not treated it can be fatal in $95 \%$ of the cases. Finally, MCL is characterized by disfiguring lesions in the nose and mouth area that leads to loss of the whole nose and palate.

Most of what is known about resistance or susceptibility to infections with Leishmania spp. is based on the host cytokine profile. While T helper (Th) type 1 lymphocyte-related cytokines are generally associated with a good prognostic (IFN- $\gamma$ and TNF- $\alpha$ ), Th2-related cytokines (IL-4, IL-5, and IL-13) and antiinflammatory cytokines (IL-10 and TGF- $\beta$ ) are associated with susceptibility (Scott et al., 1989; Heinzel et al., 1991; Reiner and Locksley, 1995).

Several studies have suggested a role of B cells in promoting infection with Leishmania spp. either directly or indirectly via production of antibody, IL-10 or $\mathrm{PGE}_{2}$ (Hoerauf et al., 1994, 1995; Palanivel et al., 1996; Smelt et al., 2000; Colmenares et al., 2002; Buxbaum and Scott, 2005; Wanasen et al., 2008; Chu et al., 2010; Deak et al., 2010; Arcanjo et al., 2015, 2017a,b; Gonzaga et al., 2015, 2017; Geraldo et al., 2016). Taking CL as example, B cells are thought to be harmful to the host response. BALB/JhD, which lacks B cell (both B-1 and B-2), present lower lesions, antibodies and IL-10 than BALB/c mice when infected by $L$. amazonensis (Wanasen et al., 2008). Furthermore, in VL caused by L. donovani it is known that: mice which lack B cells are more resistant to infection (Smelt et al., 2000); marginal zone B cells impairs T cell responses (Bankoti et al., 2012); and the antibody production (Srinontong et al., 2018) as well as the presence of B cells (Silva-Barrios et al., 2016) are linked to pathogenesis. Besides conventional B-2 cells, B-1 cells also seem to be very important in this context (Hoerauf et al., 1994; Arcanjo et al., 2015, 2017a,b; Gonzaga et al., 2015, 2017; Geraldo et al., 2016) and here we visit several works trying to summarize the main findings in the field.

B-1 cells are related in the response to several intracellular pathogens, from opportunist infections such as microsporidia, in which they are important to control the infection upregulating
$\mathrm{T} \mathrm{CD}^{+}$cells and proinflammatory cytokines (Langanke Dos Santos et al., 2018), to parasite infections. In the present work we aimed to review the current literature regarding the participation of B-1 cells in the development of Leishmania spp. infections in murine models.

\section{THE ROLE OF B-1 CELL DURING LEISHMANIA MAJOR INFECTION}

BALB/Xid mice have a mutation in the Bruton's tyrosine kinase, which is an important enzyme for developing B-1 and maturing B-2 lymphocytes (Tsukada et al., 1993) leading to the presence of immature B-2 cells (Oka et al., 1996). BALB/Xid mice infected in the footpad with $L$. major present delayed lesion development compared to WT BALB/c mice (Hoerauf et al., 1994). In addition, $\mathrm{BALB} / \mathrm{Xid}$ mice have lower parasite loads at the inoculation site, draining lymph node and spleen at 3 weeks post-infection, but not at 5 weeks post-infection, compared to $\mathrm{WT} B A L B / c$ mice (Figure 1A) (Hoerauf et al., 1994).

Peritoneal B cells (mainly B-1) were shown to produce IL10 in vitro, and in the presence of L. major extract (Lm extract) and IL- 4 stimulus per $66 \mathrm{~h}$, the cells produce even more IL-10 than the non-stimulated control (Hoerauf et al., 1994). Moreover, intraperitoneal (i.p.) injection of $\mathrm{Lm}$ extract induces peritoneal $\mathrm{B}-1$ cell proliferation and IL-10 production in $\mathrm{BALB} / \mathrm{c}$ mice (Figure 1A), but not in C57BL/6 mice (Palanivel et al., 1996). However, peritoneal B-1 cells from C57BL/6 mice pre-stimulated with Lm extract i.p., when restimulated with the same extract in vitro are able to produce more IL-10 than the control. Peritoneal B-1 cells derived from BALB/c mice pre-stimulated with Lm extract i.p., present exacerbated IL-10 production when compared to the control (Palanivel et al., 1996). Besides that, it was shown that splenic B-1a cells are the main IL-10-producing B cell subtype during L. major infection, leading also to a strong Th2 signature (Ronet et al., 2010).

On the other hand, peritoneal B-1 cell-derived phagocytes (B-1CDP) are more susceptible than peritoneal macrophages to infection by $L$. major in vitro, with a higher percentage of infection, in terms of both the number of cells infected and the number of parasites per cell, as well as higher parasite proliferation (Figure 1B) (Arcanjo et al., 2015). This was attributed to the fact that B-1CDP produce more IL-10, lipid bodies and $\mathrm{PGE}_{2}$ endogenously than the macrophages (Figure 1B), and when the B-1CDP are treated with anti-IL10 or non-steroidal anti-inflammatory drugs that inhibit $\mathrm{PGE}_{2}$ production these cells become as susceptible as macrophages (Freire-de-Lima et al., 2000, 2006; Decote-Ricardo et al., 2017). Besides that, the treatment with non-steroidal anti-inflammatory drugs decreases the level of IL-10 produced by B-1CDP and it becomes the same as the level of IL-10 produced by macrophages (Arcanjo et al., 2015). This indicates that the IL-10 production is the key factor in the susceptibility of B-1CDP cells to $L$. major infection. To further confirm this, B-1CDP from IL-10 $10^{-/-}$ mice are significantly less susceptible to L. major than those from WT mice, with lower infection ratios and reduced parasite proliferation (Arcanjo et al., 2015). 


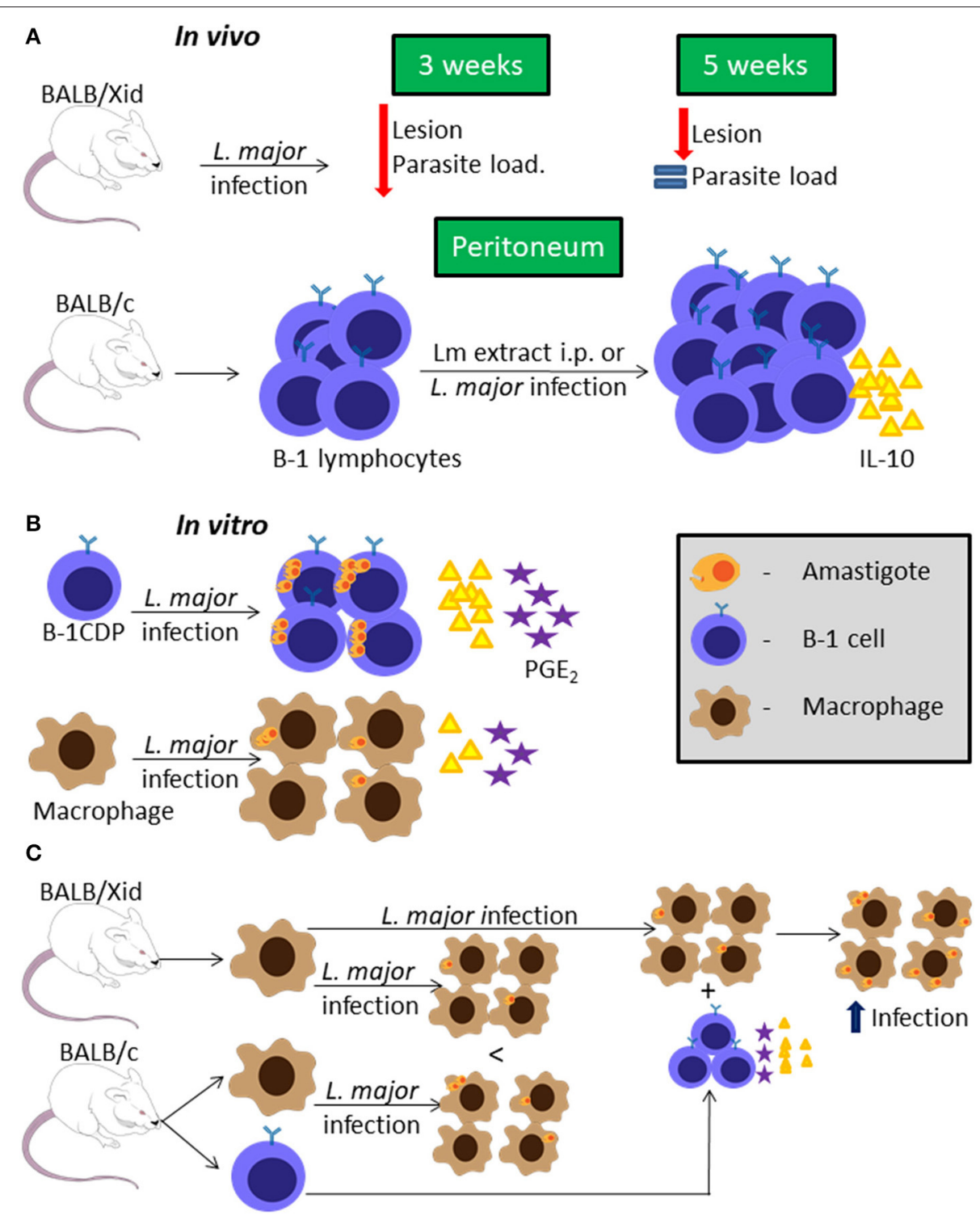

FIGURE 1 | B-1 cells and Leishmania major infection. Representative graphic scheme about in vivo infection with L. major or stimuli with L. major extract (A); in vitro infection using BALB/c cells (B); or in vitro infection comparing BALB/c and BALB/Xid derived cells (C). The schemes show a compilation of the results obtained by different research groups.

Macrophages derived from BALB/Xid mice appear to be less susceptible to L. major infection than those derived from WT BALB/c mice (Figure 1C) (Arcanjo et al., 2017a). However, the presence of $\mathrm{B}-1$ cells from $\mathrm{WT} \mathrm{BALB} / \mathrm{c}$ mice in the culture makes macrophages from both WT and BALB/Xid mice more susceptible to L. major infection in vitro and this phenomenon is not dependent on cell contact (Figure 1C) (Arcanjo et al., 2017a). Through the use of anti-IL-10 and nonsteriodal anti-inflammatory drugs, it was again confirmed that this effect on macrophage susceptibility was due to IL-10 and $\mathrm{PGE}_{2}$ (Arcanjo et al., 2017a). Furthermore, the presence of B-1 lymphocytes derived from IL-10-/- mice is not able to make macrophages susceptible as those derived from WT mice (Arcanjo et al., 2017a).
However, when $\mathrm{BALB} / \mathrm{c}$ and $\mathrm{C} 57 \mathrm{BL} / 6$ mice are lethally irradiated then reconstituted with autologous bone marrow, which leads to depletion of B-1 cells, there are no differences in the $L$. major disease progression between the B-1-depleted mice to their respective control, suggesting that B-1 cells may not be responsible for pathogenesis in this model (Babai et al., 1999).

\section{THE ROLE OF B-1 CELL DURING LEISHMANIA INFANTUM INFECTION}

In two different studies performed by two different groups, BALB/Xid mice were shown to be resistant to infection with $L$. infantum (same as L. chagasi), presenting lower splenomegaly and parasite loads in the spleen but not in the liver at final stages 
of infection (Gonzaga et al., 2015; Arcanjo et al., 2017b) probably due to lower IL-10 level in the spleen (Figure 2A) (Arcanjo et al., 2017b). However, in the early stages of infection, there is resistance of BALB/Xid mice to infection in the liver but not in the spleen (Figure 2A) (Gonzaga et al., 2015).

Infection of mice with $L$. infantum leads to an increase in the percentage of $\mathrm{CD} 19^{+} \mathrm{CD} 23^{-}$peritoneal $\mathrm{B}$ cells, and the B-1 cell repopulation of BALB/Xid mice leads to loss of the resistance by these transgenic mice and to a similar profile of $\mathrm{CD}{ }^{+} \mathrm{CD} 23^{-}$peritoneal B cell (Figure 2A) (Gonzaga et al., 2015). It was also demonstrated that the infection induces differences in intestinal compartment from mice. While BALB/c mice present decrease in the thickness of the submucosa and circular layer, BALB/Xid mice present increased thickness in those sites, but the repopulation with $\mathrm{B}-1$ reduces the increase index in these mice (Figure 2A) (Souza et al., 2019). Besides that, the infection also caused impaired quantitative goblet cells change, in the sialomucins and sulphomucins-producing goblet cells and in the number of Paneth cells (Figure 2A) (Souza et al., 2019).

Moreover, IL-10 $10^{-/}$mice show resistance to $L$. infantum infection when compared to WT C57BL/6 mice, but when

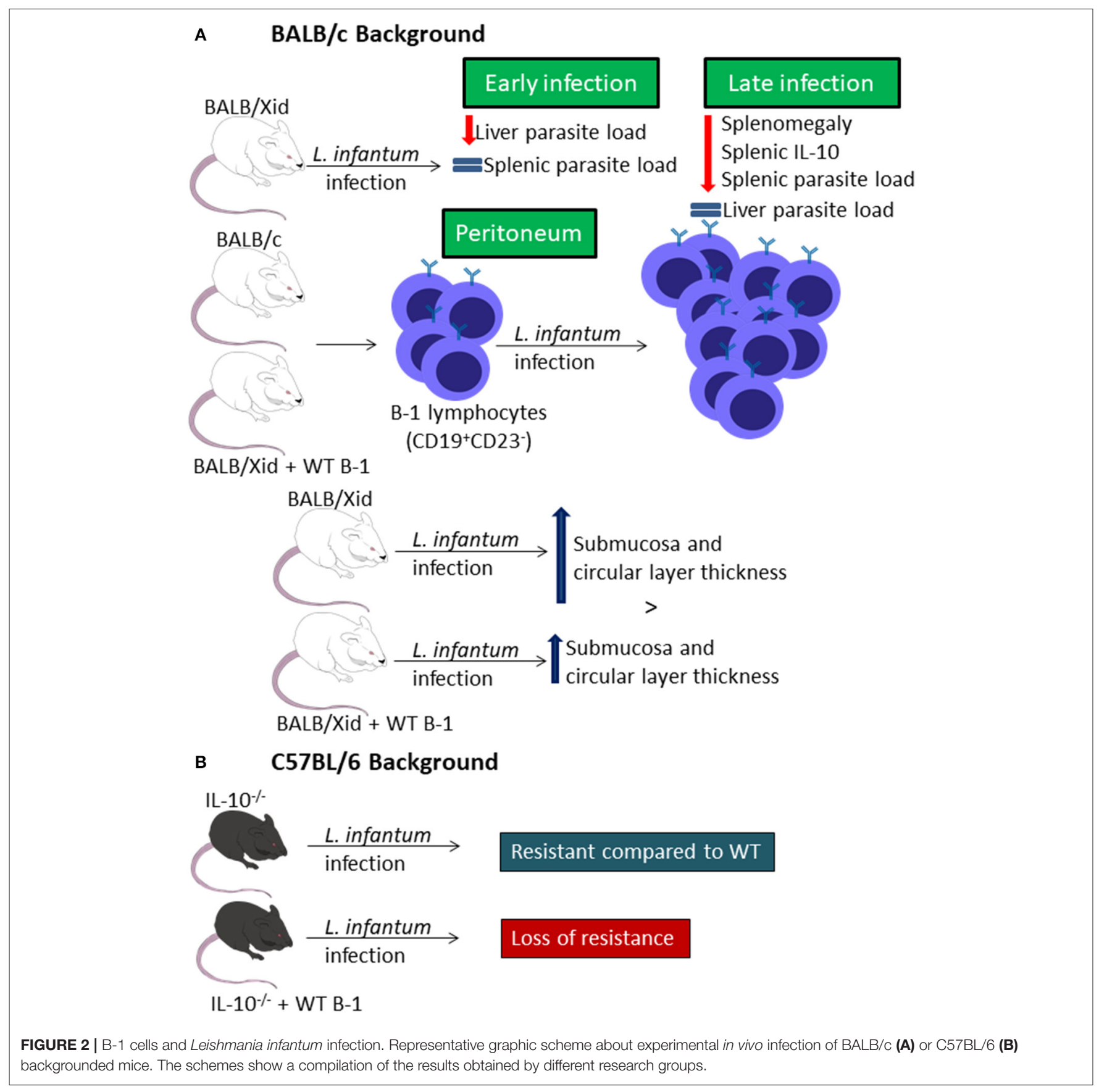


these mice receive an adoptive transfer of peritoneal B-1 cells they become as susceptible as WT C57BL/6 mice (Figure 2B) (Gonzaga et al., 2015).

\section{THE ROLE OF B-1 CELL DURING LEISHMANIA AMAZONENSIS INFECTION}

There are a few studies around the role of B-1 cells during L. amazonensis infection using two different strains, the Josefa strain (Firmino-Cruz et al., 2018) and the M2269 strain (Gonzaga et al., 2017). BALB/Xid mice showed resistance in lesion growth when compared to WT BALB/c mice in both studies (Figure 3A)
(Gonzaga et al., 2017; Firmino-Cruz et al., 2018). Despite the similarities in the lesion development, there is some conflicting data regarding the parasite load, as BALB/Xid mice present higher parasite load in the footpad of mice infected with the M2269 strain compared to infected WT BALB/c mice (Gonzaga et al., 2017), but there is no differences between the groups infected with the Josefa strain (Figure 3A) (Firmino-Cruz et al., 2018). While one group claims that the, when repopulated with B-1 lymphocytes, BALB/Xid mice present the same phenotype as BALB/c (Gonzaga et al., 2017), the other claims that this repopulation is not able to change BALB/Xid phenotype (Figure 3A) (Firmino-Cruz et al., 2019).

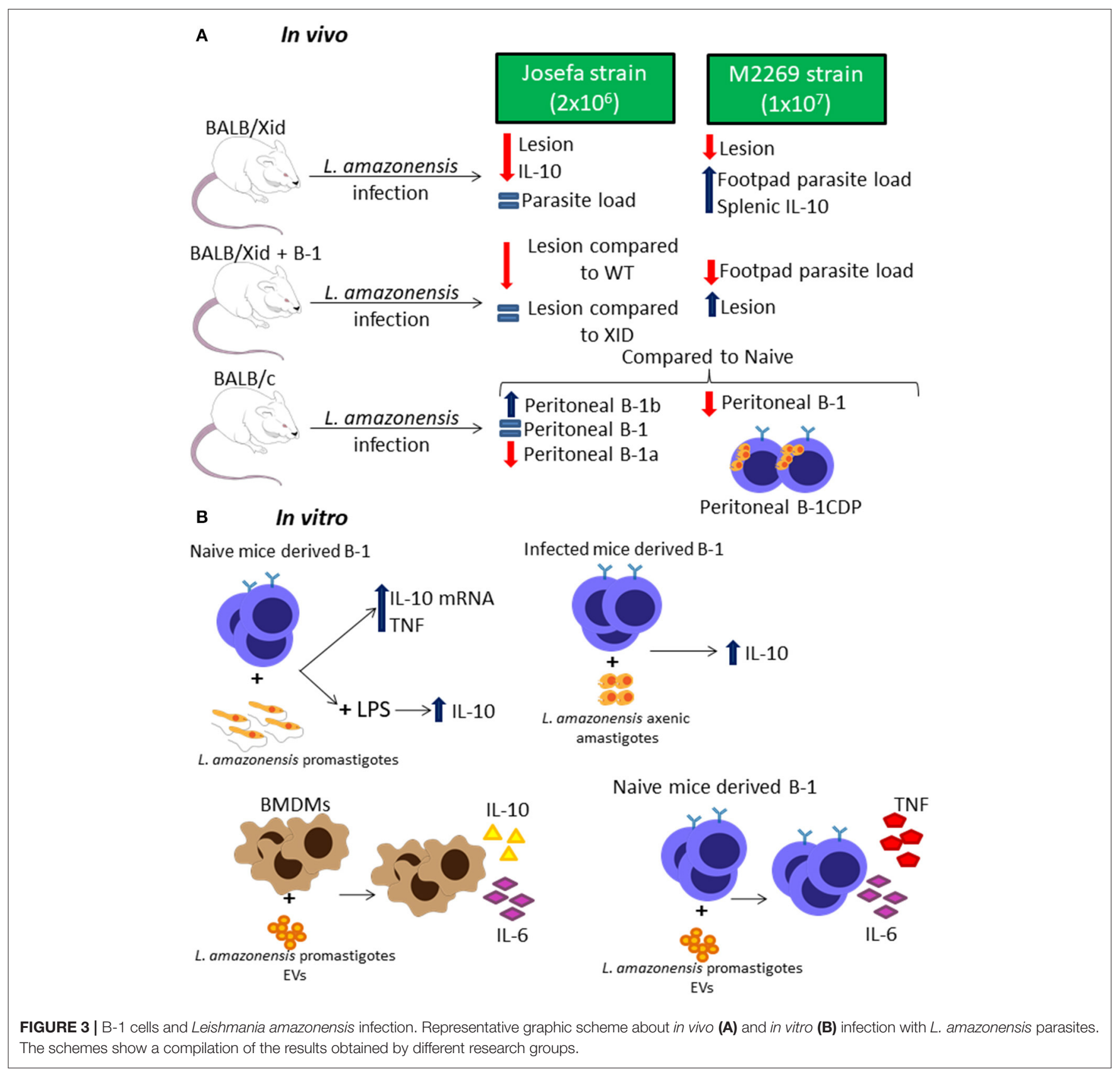


In addition, IL-10 production in these infected mice is also controversial since one group claims that BALB/Xid present a higher level of this cytokine in the spleen (Gonzaga et al., 2017), while the other shows that BALB/Xid present lower IL-10 levels in the footpads, spleen and draining lymph nodes when compared to WT BALB/c mice (Figure 3A) (Firmino-Cruz et al., 2018). It is very important to notice that the differences between these finding perhaps are related to the different parasite strain and load of infection used by each group, which can make a huge difference to the final phenotype (Loeuillet et al., 2016).

Interestingly, L. amazonensis infection modulates the B-1 cell profile in WT mice (Figure 3A) (Gonzaga et al., 2017; Firmino-Cruz et al., 2019). Besides that, the infection also alters the B-1 subtypes profile, increasing B-1b levels and severely decreasing B-1a levels (Figure 3A) (Firmino-Cruz et al., 2019). The interaction between peritoneal B-1 lymphocytes derived from naïve mice and $L$. amazonensis alone in vitro does not induce IL-10 production (Geraldo et al., 2016; Firmino-Cruz et al., 2019), even though there is an increase in the production of the mRNA of this cytokine (Figure 3B) (Geraldo et al., 2016). However, L. amazonensis is able to increase the IL-10 release caused by LPS and peritoneal B-1 cells derived from infected mice, when interacting to L. amazonensis axenic amastigotes, are able to produce more IL-10 than the ones derived from naïve mice (Figure 3B) (Firmino-Cruz et al., 2019). Moreover, the B1 cell is able to induce the production of TNF in interaction with promastigotes (Figure 3B) (Geraldo et al., 2016). Recent studies have demonstrated that L. amazonensis promastigotes are able to release extracellular vesicles (EVs) which can induce bone marrow-derived macrophages (BMDMs) to increase the expression of IL-10 and IL-6, however those EVs act in B-1 cells differently, increasing IL-6 and TNF instead of IL-10 (Figure 3B) (Barbosa et al., 2018).

B-1 cells are not able to phagocytose L. amazonensis, however, B-1CDP cells can internalize more L. amazonensis parasites than peritoneal and medullar macrophages at $16 \mathrm{~h}$ and $24 \mathrm{~h}$ of infection (Geraldo et al., 2016). This phagocytic capacity was blocked by the presence of D-mannose and anticomplement receptor 3 (CR3) (Geraldo et al., 2016). B-1CDP cells can also phagocytose L. amazonensis in vivo (Figure 3A) (Geraldo et al., 2016).

\section{CONCLUDING REMARKS}

In conclusion, the role of B-1 cells in infection by Leishmania spp. is still unclear. While a few groups were able to link pathogenesis

\section{REFERENCES}

Alugupalli, K. R., Gerstein, R. M., Chen, J., Szomolanyi-Tsuda, E., Woodland, R. T., and Leong, J. M. (2003). The resolution of relapsing fever borreliosis requires $\operatorname{IgM}$ and is concurrent with expansion of $\mathrm{B} 1 \mathrm{~b}$ lymphocytes. J. Immunol. 170, 3819-3827. doi: 10.4049/jimmunol.170. 7.3819

Arcanjo, A. F., LaRocque-de-Freitas, I. F., Rocha, J. D., Zamith, D., Costa-da-Silva, A. C., Nunes, M. P., et al. (2015). The $\mathrm{PGE}_{2} / \mathrm{IL}-10$ axis determines susceptibility with the presence of B-1 cells (Hoerauf et al., 1994; Arcanjo et al., 2015, 2017a,b; Gonzaga et al., 2015, 2017) other have shown that in vivo this is more complex (Babai et al., 1999). The fact is that the presence of Leishmania spp. seems to induce responses in B-1 cells, such as cytokine production (Babai et al., 1999; Arcanjo et al., 2015, 2017b; Gonzaga et al., 2015, 2017; Geraldo et al., 2016; Firmino-Cruz et al., 2019) and lipid body formation (Arcanjo et al., 2015, 2017a). However, the B-1 cell susceptibility to Leishmania spp. infection seems to be linked to the production of IL-10 in most of cases (Hoerauf et al., 1994; Palanivel et al., 1996; Arcanjo et al., 2015, 2017a,b; Gonzaga et al., 2015, 2017; Geraldo et al., 2016) suggesting that this cytokine promotes infection, which is not restricted to B-1 cells endogenously, but also in relation to other cells, such as macrophages (Arcanjo et al., 2017a).

There are no many papers regarding the B-1 role during infection by genus Leishmania. Most have been done with Leishmania major, Leishmania amazonensis, and Leishmania infantum. Besides that, there still many open questions: Can B-1 cells migrate to the lesion site during CL? Can they migrate to lymph nodes and act as APCs? How physiologic is B-1 CDP and how they act during the each infection? And most important, do they act the same way between species and strains?

More studies are still necessary to gain a complete understanding of B-1 lymphocytes during Leishmania spp. infection, especially because there are many species of great clinical impact that have not been checked yet.

\section{AUTHOR CONTRIBUTIONS}

LF-C, DD-R, DCOG, AM, CGFL and HG wrote the review. All authors read and approved the final version of the manuscript.

\section{FUNDING}

We received financial support from Programa Jovem Cientista do Nosso Estado (FAPERJ - E-26/202.674/2018); Productivity Fellowships from Conselho Nacional de Desenvolvimento Científico e Tecnológico (304712/20167) and Agency for Support and Evaluation of Graduate Education (CAPES) Finance code 001. The funders had no role in study design, data collection and analysis, decision to publish, or preparation of the manuscript. of B-1 cell-derived phagocytes (B-1CDP) to Leishmania major infection. PLoS ONE 10, 1-18. doi: 10.1371/journal.pone.0124888

Arcanjo, A. F., Nico, D., de Castro, G. M. M., da Silva Fontes, Y., Saltarelli, P., Decote-Ricardo, D., et al. (2017b). Dependency of B-1 cells in the maintenance of splenic interleukin-10 producing cells and impairment of macrophage resistance in visceral leishmaniasis. Front. Microbiol. 8, 1-7. doi: $10.3389 /$ fmicb.2017.00978

Arcanjo, A. F., Nunes, M. P., Silva-Junior, E. B., Leandro, M., da Rocha, J. D. B., Morrot, A., et al. (2017a). B-1 cells modulate the murine macrophage 
response to Leishmania major infection. World J. Biol. Chem. 8, 151-162. doi: $10.4331 /$ wjbc.v8.i2.151

Babai, B., Louzir, H., Cazenave, P. A., and Dellagi, K. (1999). Depletion of peritoneal CD5+ B cells has no effect on the course of Leishmania major infection in susceptible and resistant mice. Clin. Exp. Immunol. 117, 123-129. doi: 10.1046/j.1365-2249.1999.00953.x

Bankoti, R., Gupta, K., Levchenko, A., and Stäger, S. (2012). Marginal zone B cells regulate antigen-specific $\mathrm{T}$ cell responses during infection. J. Immunol. 188, 3961-3971. doi: 10.4049/jimmunol.1102880

Barbosa, F. M. C., Dupin, T. V., Toledo, M. D. S., Reis, N. F. D. C., Ribeiro, K., Cronemberger-Andrade, A., et al. (2018). Extracellular vesicles released by leishmania (Leishmania) amazonensis promote disease progression and induce the production of different cytokines in macrophages and B-1 cells. Front. Microbiol. 9, 1-14. doi: 10.3389/fmicb.2018.03056

Baumgarth, N. (2017). A Hard(y) Look at B-1 cell development and function. J. Immunol. 199, 3387-3394. doi: 10.4049/jimmunol. 1700943

Buxbaum, L. U., and Scott, P. (2005). Interleukin 10- and Fc $\gamma$ receptor-deficient mice resolve leishmania mexicana lesions. Infect. Immun. 73, 2101-2108. doi: 10.1128/IAI.73.4.2101-2108.2005

Chu, N., Thomas, B. N., Patel, S. R., and Buxbaum, L. U. (2010). IgG1 is pathogenic in leishmania mexicana infection. J. Immunol. 185, 6939-6946. doi: 10.4049/jimmunol.1002484

Colmenares, M., Constant, S. L., Kima, P. E., and McMahon-Pratt, D. (2002). Leishmania pifanoi pathogenesis: Selective lack of a local cutaneous response in the absence of circulating antibody. Infect. Immun. 70, 6597-6605. doi: 10.1128/IAI.70.12.6597-6605.2002

Cunningham, A. F., Flores-Langarica, A., Bobat, S., Dominguez Medina, C. C., Cook, C. N., Ross, E. A., et al. (2014). B1b cells recognize protective antigens after natural infection and vaccination. Front. Immunol. 5, 1-11. doi: 10.3389/fimmu.2014.00535

De Lorenzo, B. H., Brito, R. R., Godoy, L. C., Lopes, J. D., and Mariano, M. (2007). Tolerogenic property of B-1b cells in a model of allergic reaction. Immunol. Lett. 114, 110-118. doi: 10.1016/j.imlet.2007. 09.013

Deak, E., Jayakumar, A., Cho, K. W., Goldsmith-Pestana, K., Dondji, B., Lambris, J. D., et al. (2010). Murine visceral leishmaniasis: IgM and polyclonal Bcell activation lead to disease exacerbation. Eur. J. Immunol. 40, 1355-1368. doi: 10.1002/eji.200939455

Decote-Ricardo, D., Nunes, M. P., Morrot, A., and Freire-de-Lima, C. G. (2017). Implication of apoptosis for the pathogenesis of Trypanosoma cruzi infection. Front. Immunol. 8, 1-5. doi: 10.3389/fimmu.2017. 00518

Firmino-Cruz, L., Ramos, T. D., da Fonseca-Martin, A. M., Maciel, D., da Silva, G. O., dos Santos, J. S., et al. (2019). B-1 lymphocytes are able to produce IL-10, but is not pathogenic during Leishmania (Leishmania) amazonensis infection. Immunobiology. doi: 10.1016/j.imbio.2019.10.006. [Epub ahead of print].

Firmino-Cruz, L., Ramos, T. D., da Fonseca-Martins, A. M., Maciel-Oliveira, D., Oliveira-Silva, G., Pratti, J. E. S., et al. (2018). Immunomodulating role of IL10 -producing B cells in Leishmania amazonensis infection. Cell. Immunol. 334, 20-30. doi: 10.1016/j.cellimm.2018.08.014

Freire-de-Lima, C. G., Nascimento, D. O., Soares, M. B., Bozza, P. T., Castro-FariaNeto, H. C., de Mello, F. G., et al. (2000). Uptake of apoptotic cells drives the growth of a pathogenic trypanosome in macrophages. Lett. Nat. 403, 199-203. doi: $10.1038 / 35003208$

Freire-de-Lima, C. G., Xiao, Y. Q., Gardai, S. J., Bratton, D. L., Schiemann, W. P., Henson, P. M. (2006). Apoptotic cells, through transforming growth factor$\mathrm{N}_{L}$, coordinately induce anti-inflammatory and suppress pro-inflammatory eicosanoid and NO synthesis in murine macrophages *. J. Biol. Chem. 281, 38376-38384. doi: 10.1074/jbc.M605146200

Geraldo, M. M., Costa, C. R., Barbosa, F. M., Vivanco, B. C., Gonzaga, W. F., Novaes E Brito, R. R., et al. (2016). In vivo and in vitro phagocytosis of Leishmania (Leishmania) amazonensis promastigotes by B-1 cells. Parasite Immunol. 38, 365-376. doi: 10.1111/pim.12324

Gonzaga, W. F., Xavier, V., Vivanco, B. C., Lopes, J. D., and Xander, P. (2015). B-1 cells contribute to susceptibility in experimental infection with Leishmania (Leishmania) chagasi. Parasitology 142, 1506-1515. doi: $10.1017 /$ S0031182015000943
Gonzaga, W. F. K. M., Geraldo, M. M., Vivanco, B. C., Popi, A. F., Mariano, M., Batista, W. L., et al. (2017). evaluation of experimental infection with $L$. (L.) amazonensis in X-linked immunodeficient mice. J. Parasitol. 103, 708-717. doi: $10.1645 / 16-145$

Heinzel, F. P., Sadick, M. D., Mutha, S. S., and Locksley, R. M. (1991). Production of interferon gamma, interleukin 2, interleukin 4, and interleukin 10 by $\mathrm{CD} 4+$ lymphocytes in vivo during healing and progressive murine leishmaniasis. Proc. Natl. Acad. Sci. U.S.A. 88, 7011-7015. doi: 10.1073/pnas.88. 16.7011

Hoerauf, A., Solbach, W., Lohoff, M., and Röllinghoff, M. (1994). The xid defect determines an improved clinical course of murine leishmaniasis in susceptible mice. Int. Immunol. 6, 1117-1124. doi: 10.1093/intimm/ 6.8.1117

Hoerauf, A., Solbach, W., Röllinghoff, M., and Gessner, A. (1995). Effect of IL-7 treatment on Leishmania major-infected BALB.Xid mice: enhanced lymphopoiesis with sustained lack of B1 cells and clinical aggravation of disease. Int. Immunol. 7, 1879-1884.

Kantor, A. B., Stall, A. M., Adams, S., Herzenberg, L. A., and Herzenberg, L. (1992). A. Differential development of progenitor activity for three B-cell lineages. Proc. Natl. Acad. Sci. U.S.A. 89, 3320-3324. doi: 10.1073/pnas.89. 8.3320

Langanke Dos Santos, D., Alvares-Saraiva, A. M., Xavier, J. G., Spadacci-Morena, D. D., Peres, G. B., and Dell'Armelina Rocha, P. R., et al. (2018). B-1 cells upregulate CD8 T lymphocytes and increase proinflammatory cytokines serum levels in oral encephalitozoonosis. Microbes Infect. 20, 196-204. doi: 10.1016/j.micinf.2017.11.004

Loeuillet, C., Bañuls, A. L., and Hide, M. (2016). Study of Leishmania pathogenesis in mice: experimental considerations. Parasites Vect. 9, 1-12. doi: 10.1186/s13071-016-1413-9

O'Garra, A., and Howard, M. (1991). Cytokines and Ly-1 (B1) B cells. Int. Rev. Immunol. 8, 219-234. doi: 10.3109/08830189209 055575

Oka, Y., Rolink, A. G., Andersson, J., Kamanaka, M., Uchida, J., Yasui, T., et al. (1996). Profound reduction of mature B cell numbers, reactivities and serum Ig levels in mice which simultaneously carry the XID and CD40 deficiency genes. Int. Immunol. 8, 1675-1685. doi: 10.1093/intimm/8. 11.1675

Palanivel, V., Posey, C., Horauf, A. M., Solbach, W., Piessens, W. F., and Harn, D. A. (1996). B-cell outgrowth and ligand-specific production of IL-10 correlate with Th2 dominance in certain parasitic diseases. Exp. Parasitol. 84, 168-177. doi: 10.1006/expr.1996.0102

Reiner, S. L., and Locksley, R. M. (1995). The regulation of immunity to leishmania major. Annu. Rev. Immunol. 13, 151-177. doi: 10.1146/annurev.iy.13.040195.001055

Ronet, C., Hauyon-La Torre, Y., Revaz-Breton, M., Mastelic, B., Tacchini-Cottier, F., Louis, J., et al. (2010). Regulatory B cells shape the development of Th2 immune responses in BALB/c mice infected with Leishmania major through IL-10 production. J. Immunol. 184, 886-894. doi: 10.4049/jimmunol. 0901114

Scott, P., Pearce, E., Cheever, A. W., Coffman, R. L., and Sher, A. (1989). Role of cytokines and CD4+ T-cell subsets in the regulation of parasite immunity and disease. Immunol. Rev. 112, 161-182. doi: 10.1111/j.1600-065X.1989.tb00557.x

Silva-Barrios, S., Smans, M., Duerr, C. U., Qureshi, S. T., Fritz, J. H., Descoteaux, A., et al. (2016). Innate immune B cell activation by leishmania donovani exacerbates disease and mediates innate immune $\mathrm{B}$ cell activation by leishmania donovani exacerbates disease and mediates hypergammaglobulinemia. Cell Rep. 15, 2427-2437. doi: 10.1016/j.celrep.2016.05.028

Sindhava, V., Woodman, M. E., Stevenson, B., and Bondada, S. (2010). Interleukin10 mediated autoregulation of murine B-1 B-cells and its role in borrelia hermsii infection. PLoS ONE 5, 1-17. doi: 10.1371/journal.pone.0011445

Sindhava, V. J., and Bondada, S. (2012). Multiple regulatory mechanisms control B-1 B cell activation. Front. Immunol. 3, 1-6. doi: 10.3389/fimmu.2012.00372

Smelt, S. C., Cotterell, S. E., Engwerda, C. R., and Kaye, P. M. (2000). B celldeficient mice are highly resistant to leishmania donovani infection, but develop neutrophil-mediated tissue pathology. J. Immunol. 164, 3681-3688. doi: 10.4049/jimmunol.164.7.3681

Souza, K. D., Fernandes, E. P. A., Dos Santos, A. G. A., de Lima, L. L., Gonzaga, W. F. K. M., Xander, P., et al. (2019). Infection by Leishmania (Leishmania) 
infantum chagasi causes intestinal changes B - 1 cells dependent. Parasite Immunol. 41, 1-8. doi: 10.1111/pim.12661

Srinontong, P., Wu, Z., Sato, K., Nagaoka, H., and Maekawa, Y. (2018). The circulating immunoglobulins negatively impact on the parasite clearance in the liver of Leishmania donovani -infected mice via dampening ROS activity. Biochem. Biophys. Res. Commun. 506, 20-26. doi: 10.1016/j.bbrc. 2018.10.055

Stall, A. M., Adams, S., Herzenberg, L. A., and Kantor, A. B. (1992). Characteristics and development of the murine B-1b (Ly-1 B Sister) cell population. Ann. N. Y. Acad. Sci. 651, 33-43. doi: 10.1111/j.1749-6632.1992. tb24591.x

Tsukada, S., Saffran, D. C., Rawlings, D. J., Parolini, O., Allenm, R. C., Klisak, I., et al. (1993). Deficiente expression of a B cell cytoplasmic tyrosine kinase in human X-linked agammaglobulinemia. Cell 72, 279-290. doi: 10.1016/0092-8674(93)90667-F

Tung, J. W., Mrazek, M. D., Yang, Y., Herzenberg, L. A., and Herzenberg, L. A. (2006). Phenotypically distinct B cell development pathways map to the three B cell lineages in the mouse. Proc. Natl. Acad. Sci. U.S.A. 103, 6293-6298. doi: $10.1073 /$ pnas. 0511305103
Vigna, A. F., Almeida, S. R., Xander, P., Freymüller, E., Mariano, M., and Lopes, J. D. (2006). Granuloma formation in vitro requires B-1 cells and is modulated by Paracoccidioides brasiliensis gp43 antigen. Microbes Infect. 8, 589-597. doi: 10.1016/j.micinf.2005.06.033

Wanasen, N., Xin, L., and Soong, L. (2008). Pathogenic role of B cells and antibodies in murine Leishmania amazonensis infection. Int. J. Parasitol. 38, 417-429. doi: 10.1016/j.ijpara.2007.08.010

Conflict of Interest: The authors declare that the research was conducted in the absence of any commercial or financial relationships that could be construed as a potential conflict of interest.

Copyright (C) 2020 Firmino-Cruz, Decote-Ricardo, Gomes, Morrot, Freire-de-Lima and de Matos Guedes. This is an open-access article distributed under the terms of the Creative Commons Attribution License (CC BY). The use, distribution or reproduction in other forums is permitted, provided the original author $(s)$ and the copyright owner(s) are credited and that the original publication in this journal is cited, in accordance with accepted academic practice. No use, distribution or reproduction is permitted which does not comply with these terms. 